\title{
CAPACITAÇÃO PEDAGÓGICA DE ENFERMEIROS: UMA CONSTRUÇÃO A PARTIR DA CONCEPÇÃO PROBLEMATIZADORA
}

\author{
Lorena Teresinha Consalter Geib*
}

GEIB, L.T.C. Capacitação pedagógica de enfermeiros: uma construção a partir da concepção problematizadora.

Rev.latino-am.enfermagem, Ribeirão Preto, v. 9, n. 1, p. 59-65, janeiro 2001.

O artigo descreve o espaço e tempo do quotidiano acadêmico em seu deslizamento da racionalidade moderna para a socialidade pós-moderna. Utilizando um estilo estético e um recorte microssocial de abordagem compreensiva, olha para questões, como vestibular, recepção de calouros, prática pedagógica, reuniões e distribuição do saber, vislumbrando as possibilidades emergentes na (des) construção de novas relações acadêmicas.

UNITERMOS: educação em enfermagem, universidades, ciência

\section{INTRODUÇÃO}

$\boldsymbol{O}$ desafio de romper posturas acadêmicas tradicionais, moldadas pela ciência, para ousar no terreno - ainda pouco explorado - do quotidiano que a pósmodernidade apresenta com nuança de presenteísmo foi, no mínimo, inquietante.

Esse desafio de produzir um texto com as características estéticas da pós-modernidade foi proposto pela Dra. Ana Lúcia Magela de Rezende como atividade do Seminário de Controvérsias do curso de mestrado em Assistência de Enfermagem UFSC/UPF, oportunizando, ao mesmo tempo, o exercício de descrever a vida quotidiana sob um olhar compreensivo e um estilo estético e a interlocução com outras áreas do conhecimento, com as quais os profissionais de enfermagem têm pouca aproximação.

Olhar para o deslizamento paradigmático, que desmonta a nossa "lógica da espera" e nos induz à "lógica da atenção" (CRESPI, 1983), é colocarmo-nos diante da nossa própria fragilidade epistemológica. Assim, por que não começar olhando para a Academia, se é nela que se dá, de forma sistematizada, a construção do conhecimento?

Com esse desafio e ancorada na mitologia grecoromana, busquei uma visão do quotidiano acadêmico, no que ele oferece de energismo e vitalismo. A descrição tem caráter caleidoscópico, sendo, portanto, limitada em sua profundidade. Sua incompletude abre-se para a complementaridade de um novo tempo.

\section{O VESTÍBULO OLÍMPICO}

A translucidez de um tempo chamado pósmoderno permite que vislumbremos a silhueta de novos atores. Nos rituais do quotidiano acadêmico, eles afrontam o absolutismo racionalista e liberam a multiplicidade de papéis em busca de respiradouros para a asfixia da vida-nossa de todo o dia, que tenta se perpetuar no caos acadêmico.

A compreensão dos diferentes fenômenos que coexistem nesse caos requer que se penetre, pela imaginação, em suas forças intrínsecas e latentes, que, na desordem, representam a possibilidade de tudo na imorredoura tentativa de perpetuar a vida.

Comecemos, pois, a descrever o palco do mundo acadêmico, onde as diferentes personas $* *$ debatem-se na dualidade da ordem e da desordem, da racionalidade moderna e da socialidade*** pós-moderna. Local onde, sorrateiramente, a estética poética afronta a hegemonia da ciência e tenta introduzir na cena a vitalidade escondida no espaço sombrio das luzes da razão.

O ingresso no Olimpo Acadêmico obedece a um

\footnotetext{
* Enfermeira. Professor Titular do curso de Enfermagem da Universidade de Passo Fundo-RS. Mestre em Assistência de Enfermagem UFSC - Pólo Passo Fundo-RS. Endereço: Rua: Tiradentes, 400 - Ap. 601 - 99010-260 - Passo Fundo - Rio Grande do Sul - Brasil ** Termo utilizado no teatro grego para designar o personagem em cena, sob cada máscara que o ator usa

*** Expressão empregada por Maffesoli (1989) para caracterizar uma agregação social de contornos indefinidos, que ultrapassa a modernidade individualista para apresentar-se mais confusa, heterogênea e movente, com um dominante empático e uma solidariedade específica exercida no ambiente espacial (ecologia, habitat, bairro)
} 
ritual destinado a descartar pretendentes menos aptos a passar de um estado de vida a outro, através das estreitas passagens - vestíbulos. Aspirar a um papel no cenário dos doutos requer, tanto de aprendizes quanto de mestres, a experiência prévia de pertencer a um grupo seleto que conseguiu passar pelos vários filtros de acesso e ser agregado ao mundo divino do saber.

Nesse ritual de passagem - conduzido implacavelmente por Chronos, deus do Tempo - os aprendizes do Olimpo enfrentarão sentimentos de perda. Perda dos colegas, que o Olimpo, ao recusar, deixou sem rumo por conta da escola, que nada mais fez do que preparar os alunos, apenas para o que ALVES (1995, p. 3) chama de "efeito guilhotina", isto é, "o clima de terror psicológico que, por efeito dos vestibulares, contagia a vida escolar dos jovens, terror que vai aumentando à medida que os vestibulares se aproximam". Os aprendizes enfrentam, nos suntuosos pórticos do Olimpo, a tristeza da separação dos pais, do lugar onde nasceram, da casa confortável, da vida mansa ... e curvam-se ao Tempo, que devora sua jovialidade, seus momentos vividos e seus sonhos não vividos.

Convencidos pela sociedade, empurrados pelos ideais de seus pais e sem outras perspectivas onde investir a vitalidade impulsionada pelas descargas hormonais, os jovens aprendizes entregam-se ao Olimpo porque o que importa é construir o futuro. Futuro esse decidido aos 16 ou 17 anos, quando a imaturidade torna pouco claras as possibilidades e os limites profissionais.

A escolha desse futuro encobre desejos camuflados advindos das projeções e transferências dos pais em relação ao futuro de seus filhos. A indecisão da escolha submete-se às imagens sedutoras e convincentes de êxito pessoal e social de determinadas profissões, inteligentemente insinuadas nos meios de comunicação. A escolha do futuro acaba também se diferenciando nos estratos sociais elevados e inferiores. Para uns, o ingresso no Olimpo representará a possibilidade de "subir na vida", nem que seja negando os pais, a profissão dos pais, a sua categoria profissional, a sua classe social. Para outros, será apenas a ratificação de sua situação no espaço-tempo social (BIANCHETTI, 1996).

Se os principais determinantes da escolha para o ingresso no Olimpo são de ordem externa e de natureza material, o que se fará quando os sonhos amadurecerem, quando as dúvidas emergirem? Estará o oráculo de Psiquê disponível para abrigar suas angústias? Haverá no Olimpo um lugar onde o presente possa expor suas manhas, seus prazeres, suas transgressões, seus encantos? Afinal, que lugar é esse que constrói o futuro?

\section{O OLIMPO ACADÊMICO}

Localiza-se em área geograficamente determinada e criteriosamente escolhida, distante dos estressores físicos e psicológicos da vida industrializada, onde a brisa suave da arborização - exótica e alergênica - dissipa os resquícios de poluição, mas induz à rinite alérgica e desvaloriza a flora nativa, e onde os pórticos ou tótens delimitam o reino dos senhores.

Há o Templo de Têmis, onde se encerram o poder, a justiça e a lei. Eruditos, os habitantes desse Templo, amantes dos rituais, cultivam o saber acumulado, valorizam a astúcia, relativizam os papéis e os fatos sociais, driblam poderes constituídos e especializam-se na arte da transgressão.

Têmis divide com Esculápio o prestígio no Olimpo Acadêmico. Atraído por esse prestígio, anualmente, um expressivo número de candidatos cobiça ingressar nesse Templo em busca da sabedoria da cura ... ou, quem sabe, da sabedoria da conquista fácil do sucesso e da realização pessoal ... familiar ... social. Prestigiado endógena e exogenamente, Esculápio perde-se na contemplação de si mesmo, tal qual Narciso, incapaz de corresponder aos apelos de seus pares. Singulares e onipotentes, os habitantes do reino de Esculápio preservam as tradições, glorificam os princípios científicos, cultivam os rituais - especialmente do poder, da objetividade e da previsibilidade. Defensores do mito do especialista, retalham o saber e fragmentam o homem. Vivendo no mundo da certeza e da verdade, erigiram, em torno do Templo, um forte de proteção contra a insanidade de Dionísio, que insidiosamente tenta romper sua razão instrumental.

Em frente ao Templo de Esculápio reina Apolo, sempre provocante por iluminar a mente para a criação artística e por instigar o reino a defender a superioridade do belo sobre o feio, do sublime sobre o vulgar, da harmonia sobre a desordem. No Olimpo, representa o santuário da resistência passiva, concretizada na escultura inescrupulosamente denunciadora; na tela que abstrai o invisível pelo visível, num jogo duplo cínico e perene; na música insinuante, que incita à libertação da alma, ao mesmo tempo em que denuncia a subjugação do corpo ao poder disciplinador da racionalidade moderna.

Apolo, na lucidez de seu cinismo, lança seu olhar sobre os obreiros do progresso que, no reino de Hefestos, constroem as cidades, as pontes, as embarcações e as fábricas, que tornarão a vida dos mortais cada vez mais próspera e ... solitária, poluída, miserável. Impermeáveis aos apelos de viver a banalidade, quedam-se a preparar o futuro com projetos inovadores, automatizados, que transferem às máquinas a realização do trabalho, mas que não são capazes de transferir a si mesmos o direito ao lazer e à qualidade de vida implícita nos seus projetos encouraçados na cientificidade.

Discreta, Diana vigia os obreiros de Hefestos, na eterna preocupação com a preservação da fauna e da 
flora ameaçadas pelo avanço das conquistas desenvolvimentistas. Avanço que devasta os rios, que desmata as florestas nativas, que extingüe espécies animais, que desequilibra o ecossistema.

Muito próximo do reino de Diana, Ceres cultiva seus trigais e seus pomares na terra que agasalha e fertiliza a semente. Preocupada em fixar os mortais em suas próprias terras, Ceres ensina-lhes a se organizarem em sociedade, a ararem o solo, a semearem, cuidarem, colherem, debulharem e armazenarem o grão, transformando-o em farinha e pão. Cultuando o ciclo da vida dentro da interação entre homens e natureza, Ceres une-se a Diana no compromisso ecológico que, no Olimpo, soa estranho aos defensores da energia nuclear, da energia produzida a partir de recursos não renováveis e das tecnologias ambientalmente perversas. Pisando o solo devastado pelas queimadas e pelo uso indiscriminado de agrotóxicos, os habitantes do reino de Ceres percebem que a ética planetária não deve ser periférica em relação à produção da riqueza, nem à busca do equilíbrio entre alimentos e populações. Ao defender essa nova ética, reconhece que a escassez na vida dos mortais não é só econômica, mas existencial e "está relacionada com nossas necessidades de lazer e contemplação, paz de espírito, amor, vida gregária e auto-realização"(CAPRA, 1997, p. 388).

Esse insight ecológico desperta a simpatia no reino de Dionísio, Templo onde o medo se dissipa, a coragem redobra, a vida ganha esplendor. Onde a confiança no próprio poder personifica a liberdade, a contestação, a desobediência e a insubmissão aos poucos docentes dominadores. Nesse reino, emerge a paixão. Vigorosa, delirante, ela ofusca e obscurece o raciocínio, afronta a ordem e a finitude e instiga os mortais a explodirem seu vitalismo reprimido. Tal é a sua emergência que não pode ser deixada para depois, para um tempo que nunca chega, para um futuro que nada mais é do que a negação de um presente ora vibrante, ora frustrante, mas... presente vivido ... sentido ... precioso!

Presente que não se esgota num tempo linear, mas que se perpetua no afeto, no inútil, no prazeroso jogo do nada fazer para eternizar o vivido. O vivido em comum, num coletivo diversificado, de valores partilhados, onde o ser-estar junto com o outro e com a natureza constitui o vitalismo impulsionador da arte de viver.

Mas no Olimpo reina também Prometeu, o representante da dualidade homem-deus. Na luta para superar as divindades olímpicas e transformar o mundo, Prometeu ensina os mortais a penetrarem nos mistérios da natureza e no labirinto de suas próprias cabeças. Renunciando ao lazer e percorrendo o caminho vitorioso(?) do trabalho, os mortais progridem com sacrifícios na eterna luta para superar suas finitudes e alcançar o reino dos céus.
Prometeu impregna fortemente o Olimpo Acadêmico dando-lhe a conotação de Templo da Construção do Futuro - onde toda a vitalidade dos aprendizes é absorvida pelo energismo produtivista (REZENDE, 1997). Nesse reino, adia-se o bem-viver, reprime-se o prazer, refuta-se a paixão e renuncia-se ao insinuante jogo da VIDA. Este, às vezes arriscado por afrontar o previsível, mas sempre fascinante pela ousadia de viver a plenitude dos pequenos momentos de significados valorizados, que os prometéicos não compreendem por estarem cegamente comprometidos com a construção de um futuro erigido na rotina e na repetitividade massacrante do presente e alicerçado em promessas: de um mundo melhor, de dias mais felizes, de ordem e progresso, de perfeição (Oh, Apolo!).

\section{A TEATRALIDADE: OS DEUSES EM CENA}

$\mathrm{Na}$ grande cena olímpica moderna, cada divindade se propõe a reinar sobre si mesma para evidenciar a distinção e conferir identidade.

A distinção expressa a poderosa aura divina que, no Olimpo Acadêmico, muito mais do que evidenciar a pluralidade - que ultrapassa a individualização - contribui para tornar a diferença instrumento de poder. Diferenciarse torna-se imperativo para manter os valores universais, escamotear as contradições do presente, acreditar na promessa de um futuro libertador e perpetuar as estruturas sociais e as condições materiais.

Distingüir-se permite assegurar a identidade de cada reino e reduzi-lo a seu próprio território, num processo de fragmentação do saber. Individualizados e reconhecidos pela precisão de suas identidades, os deuses cercam seus conhecimentos específicos no âmbito dos seus reinos: agricultura, direito, engenharia ...

A lógica da identidade, ancorada no princípio da individualização, faz ecoar a racionalidade moderna no espaço estanque e sem partilha. O Olimpo passa a constituir-se, assim, de unidades diferenciadas, detendo - cada uma delas - um saber específico com o objetivo determinado de moldar o futuro daqueles aprendizes, que, ao retornarem ao mundo dos mortais, defrontar-se-ão com a inadequação de um saber hermético, que os preparou para um futuro que não estava além-muros, nem tinha o sabor da felicidade prometida. Lá, onde deveria ser o lugar da realização dos sonhos, continuava sendo o presente dos desafios prazerosos, da audácia contida, da incompletude que exige partilha de emoções e sentimentos comuns e desperta sentimentos de pertença.

Seria, então, o futuro, prerrogativa divina? Seria esse Olimpo o espaço da perenidade, da perfeição? É para não contaminá-lo com as extravagâncias 
presenteístas que ele se situa distante ou inacessível aos simples mortais? Por que a teatralidade do Olimpo Acadêmico distancia-se da realidade vitalista, ética e estética que anima o quotidiano?

A compreensão desses aspectos exige que situemos a Academia na temporalidade histórica do conhecimento. Embora desde a Antigüidade os filósofos se ocupassem das questões referentes ao conhecimento, este só se constituiu como disciplina autônoma na modernidade, a partir de pensadores como Descartes, que imbutiram na Academia a crença de que "o método científico é a única abordagem válida do conhecimento"(CAPRA, 1997, p. 28). Essa racionalidade científica impulsionada pelo iluminismo e pelo cientificismo do século XIX consolidou uma mudança profunda no pensamento, percepção e valores que configuram uma determinada visão de mundo. Contagiados por essas concepções, os deuses do Olimpo Acadêmico deixaram-se cegar por sua "verdade". Insensíveis às investidas de Dionísio, os deuses exaltaram a capacidade de conhecer o mundo por meio da ciência e de suas virtudes: o rigor, a objetividade e a previsibilidade. $\mathrm{Na}$ ciência e na razão, encontraram as armas necessárias para espantar "o medo causado pela ignorância e superstição, guardando a esperança de um mundo onde as luzes da razão permitiriam a melhor qualidade de vida possível e a emancipação dos preconceitos, da violência e do arbítrio" (ARANHA \& MARTINS, 1990, p. 132).

O Olimpo curvou-se aos princípios da modernidade, elegendo Prometeu como seu legítimo representante, uma vez que "o prometeísmo energiza todo ato, tudo se torna controlável para que não haja desperdício, nem de tempo, nem de movimento, nem de sentimento ..."(REZENDE, 1995, p. 86). Tempo é dinheiro, e o progresso não pode esperar. Em seu nome e na expectativa de um futuro paradisíaco, os olímpicos aprisionaram toda a insinuação dionísica e jogaram-se cegamente a uma prática racional, desumana, individualista, corroedora. A uma prática que os devorava, como a águia devorava o fígado de Prometeu, que os aprisionava com seus grilhões. $\mathrm{Na}$ exaustão, começam a perceber uma silhueta que surge em cena, ainda pouco nítida porque encoberta nas sombras que seus olhos, ofuscados pelas luzes racionalistas, antes não enxergavam. Aos poucos, o vulto se aproxima, liberta-os dos grilhões e oferece-lhes as máscaras que lhes permitirão atuar no palco de um tempo chamado pósmoderno.

Gradativamente, os deuses entram em cena e descobrem que "a máscara pode ser trocada e que sobretudo se integra numa variedade de cenas, de situações que só valem porque são encenadas no plural" (MAFFESOLI, 1989, p. 31). No palco, percebem que, no convívio com o outro, na capacidade de experimentar e de sentir em comum, a diferença que antes servia para os identificar, fortalecer e separar é a mesma que agora os agrega, que substitui uma sociedade racionalizada por uma socialidade empática.

As personas descobrem a versatilidade de papéis [que as máscaras lhes permitem desempenhar]. Descobrem que o tempo é circular, provisório; que sua divindade deve ser relativizada, que sua verdade é falível; que sua humanidade é feita de momentos vividos ... de banalidades com significados ... de lazer e prazer ... de liberdade ... de comédia e tragédia ... de sátira e astúcia...

\section{AS MÁSCARAS ... CAEM?}

Agora compreendem melhor por que os aprendizes do Olimpo Acadêmico eram confusos, heterogêneos, irrequietos. Sempre preocupados em viver cada momento como se fosse o último. A começar pelo rito de iniciação materializado no "trote dos bixos"****, passam a entender por que o ingresso no Olimpo resultado de tanto esforço, competitividade e sacrifício converte-se em um cerimonial de escárnio e jocosidade, em que o trote serve como um espaço de liberdade e de contestação às normas olímpicas. Para libertar-se da opressão, substituem a afronta direta pelo barro, pelas tintas, pelo álcool. Sujando seus colegas com as cores de Apolo e inebriando-os com o néctar de Dionísio, os veteranos investem na transgressão a sua súplica pelas trivialidades orgiásticas negadas neste quotidiano. Sufocados durante um ano pelas adversidades não imaginadas, muitas vezes ultrapassam os limites da animalidade, como ocorreu recentemente com dois estudantes de medicina. Um deles resultou com queimaduras severas e outro morreu por afogamento, em decorrência dos trotes. Nesse caso, o pacto do silêncio calou as vozes dos colegas, fazendo valer a "solidariedade orgânica" como refúgio ao olhar dos deuses, que, no entanto, se faz mais compreensivo.

Com esse novo olhar, os deuses também percebem a resistência passiva dos mestres diante da rigidez normatizadora de suas atividades acadêmicas. Homogeneizados e diluídos num sujeito coletivo - corpo docente - e identificados apenas com o seu reino enfermagem, medicina, direito, agronomia ...- os mestres lançam mão de sua astúcia para romper o trabalho repetitivo e normalizador e transcender a individualização

**** Expressão empregada para designar a recepção realizada pelos veteranos aos calouros de um curso universitário 
limitadora. Abrem-se para uma "socialidade contemporânea, muito mais confusa, heterogênea, movente" (MAFFESOLI, 1989, p. 32), onde as personas movimentam-se em espaços partilhados, exercendo a pluralidade de suas máscaras, num "espaço vivido em comum, onde circulam as emoções, os afetos, os símbolos, o espaço onde se inscreve a memória coletiva, o espaço, enfim permitindo a identificação". Ingressam no espaço translúcido da pós-modernidade, que transcende a noção da identidade moderna, a qual conferia um social racionalizado, mecânico e finalizado em contornos bem definidos para se abrigar num novo espírito do tempo, onde a participação com outras divindades na totalidade olímpica assegura-lhe o papel e a coexistência num conjunto "onde tudo faz o corpo" num espaço de identificação.

Na lucidez de um cinismo, que não permite mais sufocar a vitalidade emanada de um quotidiano que quer ser vivido com as graças e desgraças do presente, a academia desperta. Despertando, inquieta-se diante das novas possibilidades ainda nebulosas, porque encobertas pela couraça racionalista. Ser desafiado a existir, a seduzir e ser seduzido, a inebriar-se no prazer e na paixão da pós-modernidade representa abdicar das posturas perenes, dos modelos de perfeição, da busca permanente do reino eterno, de um status de divindade, para assumir a humanidade feita de trivialidade, provisoriedade, falhas, encantos, desencantos.

Um pouco dionísicos, um pouco prometéicos, deuses e mestres reúnem-se para o grande Conselho Olímpico. Diante do estremecimento dos pilares que alicerçam o Universo do Saber, é preciso rever as estruturas dos templos, seus símbolos e signos.

Acostumados com um reino que se apresentava definido a seu olhar, assustam-se com a perspectiva das mudanças, requeridas a partir da quebra paradigmática que vai se tornando tão visível na pauta do Conselho, quanto o são as artimanhas utilizadas no espaço pedagógico.

Uma delas centra-se no compromisso escrito chamado Programa de Ensino, perfeitamente construído para atender aos reclamos burocráticos da instituição e jeitosamente descumprido no espaço solene da aula, sempre paga, mas nem sempre cumprida. Não nos referimos aqui apenas à presença física dos mestres, mas a sua atuação efetiva no processo de ensinar a aprender, que clama pela dialogicidade obscurecida na prática pedagógica tradicional, responsável pela transformação das aulas em monólogos indigestos. Comum, nesses casos, é constatar-se o absolutismo docente, que considera sua explicação suficientemente clara, não se dignando a responder dúvidas de "alunos que não têm as mínimas condições de estar no terceiro grau". Ou, então, a atitude arrogante de ridicularizar o aluno que formula a questão, jogando no silêncio mortal aqueles tímidos incapazes de suportar a "gozação" geral.

As artimanhas estendem-se também ao currículo oculto, mecanismo através do qual a escola passa aos aprendizes valores ocultos nos conteúdos, mas disseminados nas atitudes docentes, nos textos, nos manifestos dos murais, nas reuniões nos corredores... Essas, aliás, geralmente mais construtivas e criativas do que aquelas enfadonhas e formais que alimentam o quotidiano acadêmico.

Num clima onde começa a despertar o antimodernismo irracional e a desvelar-se os custos sociais e culturais advindos da fragmentação da ordem estabelecida, os deuses caem numa atmosfera de insegurança. Percebem que os antigos critérios científico-racionais - não são mais suficientes para cobrir a realidade, mas desconfiam profundamente dos novos. Vivem a frustração com os grandes projetos coletivos que apontavam para uma solução no futuro - que não aconteceu. Percebem que algo está nascendo, mas não o vêem claramente delimitado. Então, nessa intransparência, percebem que a sociedade desloca-se da universalidade para a fragmentação; dos espaços públicos (missas, cultos) para os espaços individuais ( anjos, altares privados); do futuro para o passado, e da verdade para as verdades. Dos grandes projetos, parte-se para as soluções imediatas e práticas. O momento, diz DIEHL (1999, p. 2), "é dos cotidianos íntimos da vida, das experiências micro, a vez é das bruxas, das feiticeiras, dos loucos, dos vadios, dos gestos significativos tais como o medo, o desejo, a angústia, etc". Retorna-se ao passado, desistindo da busca prospectiva da redenção do homem no futuro. Retorna-se ao indivíduo, abdicando-se de projetos assentados na perspectiva da mudança social.

Nesse cenário difuso, percebem que não bastam as máscaras para garantir os papéis. É preciso interpretação. E a interpretação começa no atraso sistemático aos horários estipulados; continua na fuga velada da conversa descontraída que "antecede" a reunião que já poderia ter terminado; mantém-se nos comentários paralelos e quase sempre cínicos que alimentam a deliciosa cumplicidade, materializando-se nos bilhetes rabiscados de zombarias ou nos panfletos, às vezes difamatórios, que incendeiam os processos eleitorais. São formas de resistência passiva que se expressam na astúcia, no jogo duplo, na transgressão para relativizar a ordem prometéica e a desordem dionísica, expondo o quotidiano com seus riscos e contradições.

Inebriados e inseguros, os deuses trocam as máscaras e aprimoram suas interpretações para ajustarse aos novos cenários. Enquanto os mestres hesitam, os aprendizes transgridem. Vigilantes ao poder materializado nas normas e regimentos acadêmicos e exercido nas atitudes disciplinadoras das salas de aula - 
os aprendizes armam-se para o contra-ataque sutil. À ordem estabelecida pela disposição das classes em fileiras controláveis, reagem com a desordem pueril de aviões que sobrevoam as cabeças encobertas de princípios e os corações esvaziados de paixão. À severidade de um exame cuja finalidade é muito menos uma etapa do processo de aprendizagem do que uma prática autoritária, classificatória e punitiva (LUNARDI, 1995, p. 86), os aprendizes respondem com a "cola" cada vez mais elaborada, inteligente e debochada. Burlar a norma, contestar a autoridade, driblar a sanção são mecanismos de sagacidade e astúcia que se consolidam num processo de solidariedade orgânica, apoiada na incompletude de cada um e na mutabilidade dos papéis, que, na teatralidade acadêmica, esboçam nova forma de ser e estar com o outro, num "conjunto onde tudo faz o corpo" (MAFFESOLI, 1989, p. 33) na dinâmica construção da socialidade.

A adesão a esse novo viver induz a uma atitude de entrega ao inesperado, à efemeridade, à compreensão de um ser humano concreto e plural, capaz de aceitar a diversidade de valores e de valorizar a banalidade da paixão.

Os atores desse novo tempo percebem-se hesitantes, pois, emergindo da sombra de um tempo que ainda não se foi, vêem-se compelidos a subir ao palco de um tempo em vias de se fazer. Sem mostrar-se por inteiros, instigantes e sedutores, os atores da pós-modernidade reafirmam-se como personas que renascem em cada ato para perpetuar o imaginário no teatro da vida.

\section{CONSIDERAÇÕES FINAIS}

A Academia, tida como espaço privilegiado na construção do saber, vê abalada sua estrutura epistemológica numa crise paradigmática que a desafia para a desconstrução de outro referencial científico.

A intransparência teórica aponta para um modelo subjetivista que não está claramente delimitado, mas que evidencia sinais de retorno ao indivíduo e ao passado em uma perspectiva microssocial.

Nessa atmosfera de insegurança, a Academia rediscute os critérios de cientificidade e o retorno ao quotidiano com a valorização do estilo estético-lúdico. Em seu interior, as pessoas movimentam-se num espaço de reconstrução, utilizando-se de certa passividade diante da crise de uma "Ciência com projeto de futuro". No processo de relativizar o parâmetro de Verdade, os atores movimentam-se com jogo duplo, astúcia e transgressão em busca de critérios de plausibilidade que permitam ao mundo acadêmico estabelecer uma relação dialógica com o quotidiano, como práxis social.

\section{NURSES' PEDAGOGICAL TRAINING: A CONSTRUCTION FROM THE PROBLEM-BASED CONCEPTION}

This article describes the environment and the time of academic daily work in its transition from modern rationality to post-modern sociality. By means of an esthetic style and a comprehensive-approach micro-social outline, it looks into questions such as the university entrance exams, reception of freshmen, pedagogical practice, meetings and knowledge distribution, searching for emerging possibilities in the (de)construction of new academic relations.

KEY WORDS: nursing education, universities, science

\section{CAPACITACIÓN PEDAGÓGICA DE ENFERMEROS: UNA CONSTRUCCIÓN A PARTIR DE LA CONCEPCIÓN PROBLEMATIZADORA}

El artículo describe el espacio y tiempo del cotidiano académico en su deslizamiento de la realidad moderna para la sociedad pós-moderna. Utilizando un estilo estético y un recorte microsocial de abordaje comprensivo, mira para aspectos tales como el examen pre-universitario, la recepción de los alumnos principiantes, la práctica pedagógica, reuniones y distribución del saber, vislumbrando las posibilidades que surgen de la "desconstrucción” de nuevas relaciones académicas.

TÉRMINOS CLAVES: educación en enfermería, universidades, ciencia

\section{REFERÊNCIAS BIBLIOGRÁFICAS}

01. ALVES, R. O fim dos vestibulares. Folha de São

Paulo, São Paulo, 6 fev. 1995. Caderno 1, p. 3.
02. ARANHA, M.L.de A.; MARTINS, M.H.P. Filosofando: introdução à filosofia. São Paulo: Moderna, 1990. 
03. BIAnCHETt, L. Angústia no vestibular: indicações para pais e professores. Passo Fundo: Ediupf, 1996.

04. CAPRA, F. O ponto de mutação. São Paulo: Cultrix, 1997.

05. CRESPI, F. Le risque du quotidien Trad. de Ana Lúcia Magela de Rezende. Cahiers Internationaux de Sociologie, Paris, v. 74, p. 39-45, 1983.

06. DIEHL, A.A. Os ruídos e o veleiro (o futuro no passado). O Nacional, Passo Fundo, 3 mar. 1999, Opinião, p. 2.

07. LUNARDI, V.L. A sansão normalizadora e o exame: fios visíveis/invisíveis na docilização dos corpos das enfermeiras. In: WALDOW, Vera R.; LOPES, Marta J.; MEYER, Dagmar E. Maneiras de cuidar maneiras de ensinar: a enfermagem entre a escola e a prática profissional. Porto Alegre: Artes Médicas, 1995.
08. MAFFESOLI, M. Les tribus em scéne Trad. por Ana Lúcia Magela de Rezende. Magazine Litterraire, Paris, n. 264, p. 31-33, abr. 1989.

09. MITOLOGIAS. 2. ed. São Paulo: Abril Cultural, 1979. v.1, v. 2, v. 3.

10. REZENDE, A.L.M. A harmonia da desordem: sofrimento e transgressão no trabalho de saúde. Rev. Enfermagem UERJ, Rio de Janeiro, v. 3, n. 1, p. 85-92, maio 1995.

11. REZENDE, A.L.M. Quotidiano, saúde e doença: um olhar compreensivo. In: POLAK, Y.N.de S.; KALEGARI, D.R.G.; JOUCLAS, V.M.G. (Org.). Saúde do adulto: um enfoque multidisciplinar. Curitiba: Pinha, 1997. p. 57-76. 